\title{
Non-invasive assessment of early cardiac involvement in systemic sclerosis
}

\author{
G.S.Butrous, Pauline M. Dowd ${ }^{1 *}$, J. Milne, D.S. Dymond, J. Caplin and \\ A.J. Camm \\ Departments of Cardiology and 'Dermatology, St Bartholomew's Hospital, London EC1, UK.
}

\begin{abstract}
Summary: Twenty-eight patients with wide spectrum organ involvement of progressive systemic sclerosis but without signs or symptoms suggestive of cardiac involvement were studied by non-invasive cardiac techniques. The 12-lead electrocardiogram showed abnormalities in 6 patients: one had abnormal $T$ waves and 5 had complete or incomplete right bundle branch block. Twenty four hour ambulatory electrocardiography demonstrated higher average heart rates than in similar aged controls $(82 \pm 9 \mathrm{vs}$ $\mathbf{7 4} \pm 9$ beats/min, $P<\mathbf{0 . 0 5}$ ). In one patient a short run of ventricular tachycardia was recorded. No other significant arrhythmia was documented. Echocardiographic measurements were within normal ranges but small pericardial effusions were observed in two patients (7\%). Resting first pass radionuclide angiography, utilizing $12 \mathrm{mCi}$ of technetium $99 \mathrm{~m}$ were performed in 23 patients. Seven patients $(30 \%)$ had abnormal wall motion (diffuse hypokinesia), with a significant decrease in ejection fraction in comparison to those with normal wall motion $(44 \pm 6 \% v s 60 \pm 6 \% P<0.01)$. Those with abnormal wall motion had suffered the disease longer than those with normal wall motion $(13 \pm 4 \mathrm{vs} 9.5 \pm 7 \mathrm{y})$. In conclusion, the heart is involved in half of the patients in this series; non-invasive cardiac assessment is useful in disclosing the early cardiac involvement and may influence long-term management.
\end{abstract}

\section{Introduction}

Systemic sclerosis is a disease of unknown aetiology characterized by excessive fibroblastic activity and collagen deposition which can involve several organs of the body, including the heart. Pathological studies have revealed in $12-80 \%$ of cases that fibrosis can occur in any part of the heart (D'Angelo et al., 1969; Bulkley et al., 1976), but it is often clinically unrecognized (Botstein \& Le Roy, 1981). The early detection of cardiac involvement may have important prognostic implications as sudden cardiac death has been associated with this disease (Marinato et al., 1981; Oram \& Stokes, 1961; Bulkley et al., 1978; James, 1974; Roberts \& Cabeen, 1980). In this study 28 patients with a wide spectrum of organ involvement by systemic sclerosis but with no cardiac symptoms were studied by electrocardiography, echocardiography and nuclear scintigraphy in order to discover early cardiac involvement.

Correspondence: G.S. Butrous, M.B., Ch.B.

Accepted: 27 February 1985

\section{Methods}

\section{Patients}

Twenty eight patients, 21 women and 7 men, with systemic sclerosis were studied. The mean age was $48 \pm 13$ y (mean \pm s.d.) and the patients had suffered from systemic sclerosis for a mean of $11 \pm 6 \mathrm{y}$. Table I shows the clinical details of the patients and the spectrum of organ involvement which was discovered either clinically or during investigation. Skin involvement was subdivided into calcification, sclerosis and telangiectasia. Raynaud's phenomenon was investigated by thermography including a cold stress test. Gastrointestinal and pulmonary involvement were diagnosed clinically, radiologically and by pulmonary function tests. Renal function was assessed by estimation of blood urea, serum electrolytes, serum creatinine and a creatinine clearance test. Metabolic studies included liver function tests, blood glucose, serum calcium and phosphate levels. Musculoskeletal involvement was detected by examination of stiffness, fixity and range of joint movement. Non-specific

(C) The Fellowship of Postgraduate Medicine, 1985 
Table I The clinical data of patients involved in this study

\begin{tabular}{|c|c|c|c|c|c|c|c|c|c|c|c|}
\hline No. & Age & Sex & Duration & $\begin{array}{l}\text { Skin } \\
C S T\end{array}$ & Ren & $G I T$ & Pul & Renal & $\begin{array}{c}\text { Muscular } \\
\text { Skeletal }\end{array}$ & Metab & Non $s p$ \\
\hline 1 & 46 & $\mathbf{F}$ & 2 & -++ & + & + & + & - & + & - & + \\
\hline 2 & 54 & $\mathrm{~F}$ & 20 & -++ & + & + & - & - & + & - & - \\
\hline 3 & 52 & $\mathrm{~F}$ & 20 & -++ & + & - & - & - & - & - & - \\
\hline 4 & 70 & $\mathrm{~F}$ & 20 & -++ & + & + & - & - & + & - & + \\
\hline 5 & 54 & $F$ & 3 & +++ & + & + & + & + & + & + & + \\
\hline 6 & 31 & $\mathrm{~F}$ & 10 & -++ & + & + & - & - & - & - & - \\
\hline 7 & 45 & $\mathbf{M}$ & 2 & -++ & + & - & - & - & + & - & - \\
\hline 8 & 20 & $\mathbf{M}$ & 10 & -+- & + & - & + & - & + & - & - \\
\hline 9 & 42 & $\mathbf{F}$ & 15 & ++- & + & - & - & + & + & - & - \\
\hline 10 & 37 & $\mathbf{F}$ & 10 & -+- & + & - & + & - & - & - & - \\
\hline 11 & 36 & $\mathrm{~F}$ & 10 & -++ & + & + & - & - & - & - & - \\
\hline 12 & 32 & $\mathbf{M}$ & 1 & $+t+$ & + & + & + & - & - & - & - \\
\hline 13 & 54 & $\mathbf{F}$ & 15 & -++ & + & + & - & - & - & - & + \\
\hline 14 & 50 & $\mathbf{F}$ & 6 & +++ & + & + & + & - & + & - & + \\
\hline 15 & 53 & $\mathbf{M}$ & 2 & -+- & + & - & - & - & - & - & - \\
\hline 16 & 63 & $\mathbf{F}$ & 7 & -++ & + & + & - & - & - & - & - \\
\hline 17 & 38 & $\mathbf{F}$ & 9 & --+ & + & - & - & - & - & - & - \\
\hline 18 & 41 & $\mathbf{F}$ & 22 & -+- & - & - & + & - & - & + & - \\
\hline 19 & 30 & $\mathbf{F}$ & 9 & +++ & + & + & + & - & + & - & + \\
\hline 20 & 50 & $\mathbf{F}$ & 14 & -++ & + & + & + & - & + & - & + \\
\hline 21 & 70 & $F$ & 16 & -++ & + & - & - & - & + & - & + \\
\hline 22 & 54 & $\mathbf{F}$ & 9 & +++ & + & + & + & - & + & - & + \\
\hline 23 & 65 & $\mathbf{F}$ & 20 & -++ & + & + & + & - & - & - & - \\
\hline 24 & 43 & $\mathbf{F}$ & 5 & -++ & - & + & - & - & - & - & - \\
\hline 25 & 59 & $\mathbf{M}$ & 6 & -++ & + & + & - & - & - & - & - \\
\hline 26 & 51 & $\mathrm{~F}$ & 5 & +-- & + & + & - & - & - & + & + \\
\hline 27 & 66 & $\mathbf{M}$ & 12 & +++ & + & + & + & - & - & - & - \\
\hline 28 & 45 & $\mathbf{M}$ & 15 & $++t$ & + & + & - & - & - & - & + \\
\hline
\end{tabular}

$C=$ calcification; $\mathrm{S}=$ sclerosis; $\mathrm{T}=$ telangiectasia; Ren $=$ Raynaud's phenomenon; GIT = gastrointestinal tract; Pul = pulmonary; Metab = metabolic abnormalities; Non-sp = non specific (see text).

symptoms included malaise, weakness, lassitude and anorexia.

\section{Protocol of the study}

The study was performed on an outpatient basis. Informed consent was obtained in all cases.

\section{Electrocardiographic study}

A 12-lead electrocardiogram was obtained from each patient. Twenty four hour ambulatory electrocardiograms were recorded using a 'Tracker' $24 \mathrm{~h}$ tape recorder. The tapes were then analysed by a Pathfinder analyser (Reynolds Medical, UK). The hourly minimum, maximum and average heart rates and $24 \mathrm{~h}$ trends were obtained. The electrocardiographic criteria used in this study were defined according to the Minnesota code (Prineas et al., 1982) and the rhythm disturbances were defined as follows: Sinus tachycardia:sinus rate of 120 beats/min or more. Sinus bradycardia: sinus rate of 50 beats/min or less. Sinus arrhythmia: $>20 \%$ variation of $R R$ interval from the preceding cycle. Sinus pause: PP interval more than $1.7 \mathrm{~s}$. Ventricular ectopics were classified according to Lown's classification (Lown \& Wolf, 1971). Ventricular tachycardia: more than 5 successive ventricular beats at a rate more than 120 beats/min.

\section{Echocardiographic study}

On the day of the electrocardiographic study an $\mathbf{M}$ mode echocardiogram was performed in both the supine and the semi left lateral position. Recording of all cardiac chambers and valves was attempted. The echocardiographic measurements were according to the recommendation of the American Society of Echocardiography (Sahn et al., 1978).

\section{Nuclear angiogram}

Resting first pass radionuclide angiography was performed on the same or the following day as the above studies. A bolus of $12 \mathrm{mCi}$ of technetium-99m as 
pertechnetate was injected through an ante-cubital vein followed by a rapid $20 \mathrm{ml}$ saline flush. The dynamic data were collected at $30 \mathrm{~ms}$ framing intervals and the counts continued for 1000 frames (for $30 \mathrm{~s}$ ), using a computerized multicrystal gamma camera (Baird Corporation, System 77). All studies were performed in the anteroposterior projection and data were corrected for flood field non-uniformity and instrument dead-time (Dymond et al., 1979). Total left ventricular ejection fraction (LVEF) was calculated from the background corrected activity curve generated from the $L V$ region of interest. Regional wall motion was estimated visually by superimposing end systolic and end diastolic perimeters and from regional ejection fraction images (Dymond et al., 1980).

\section{Results}

\section{Electrocardiography}

Surface 12-lead electrocardiogram Six patients had abnormalities in their 12-lead electrocardiogram. In one patient there were $Q$ waves and flat $T$ waves in V4-V6, in 2 patients there was right bundle branch block (RBBB) and in 3 patients there was incomplete RBBB.

Heart rate changes during 24-hour monitoring The average heart rate during the 24 hour recording in all patients was $82 \pm 9$ beats/min with a range of $59 \pm 9$ to $122 \pm 17$ beats $/ \mathrm{min}$. The mean heart rate was significantly higher $(P<0.05)$ than that of a standard middle-aged population of normal males and females (74 \pm 9 , range 53-95 beats/min; Bjerregaard, 1983). This observation held true for both waking and sleeping periods (awake: $83 \pm 13$ compared with asleep: $71 \pm 10$ beats $/ \mathrm{min}$ ).

Cardiac arrhythmias Sinus rhythm was predominant in all patients in this study. In $14 \%$ of the patients isolated atrial premature complexes were seen. Two patients had an occasional bout of atrial fibrillation for 2-4 s. One had sporadic 5:4 atrioventricular Wenckebach block during sleep only and one other had occasional Mobitz II AV block. One patient had one short run ( $3 \mathrm{~s})$ of ventricular tachycardia (Table II).

\section{Echocardiography}

The echocardiographic measurements in these patients were within normal limits (Table III). No abnormalities were seen in wall or valve motion. Fourteen patients $(50 \%)$ showed some evidence suggestive of a thickened pericardium according to the criteria of Schnittger et al. (1978) but there was no evidence of constrictive pericarditis. The mean mitral
Table II The spectrum of cardiac arrhythmia in patients involved in this study

\begin{tabular}{lcc}
\hline Rhythm & No. of patients & Percentage \\
\hline Sinus tachycardia & 18 & 64 \\
Sinus bradycardia & 3 & 11 \\
Sinus pauses (>1.7 s) & 0 & 0 \\
Sino-atrial block & 1 & 4 \\
Sinus arrhythmia & 7 & 25
\end{tabular}

Supraventricular arrhythmia

$\begin{array}{llr}\text { Atrial premature beats } & 4 & 14 \\ \text { Atrial fibrillation } & 2 & 7 \\ \text { Mobitz II AV block } & 1 & 4 \\ \text { Wenckebach AV block } & 1 & 4\end{array}$

Wenckebach AV block $\quad 1 \quad 4$

\begin{tabular}{lcr}
\multicolumn{3}{c}{ Ventricular } \\
VPC $<30 / \mathrm{h}$ arhthmia \\
VPC $>30 / \mathrm{h}$ & 8 & 29 \\
Multimorphological VPC & 2 & 7 \\
Couplets & 1 & 4 \\
R on T & 1 & 4 \\
Ventricular tachycardia & 0 & 0 \\
\end{tabular}

$\mathrm{VPC}=$ ventricular premature complexes; $\mathrm{AV}=$ atrioventricular.

EF slope in these patients was $8.1-16.5 \mathrm{~cm} / \mathrm{s}$. A small pericardial effusion was demonstrated in 2 patients $(7 \%)$ associated in both cases with echocardiographic evidence of pericardial thickening.

\section{Left ventricular nuclear angiography}

Twenty three patients had nuclear angiographic studies ( 5 declined this part of the study). The mean ejection fraction was $56 \pm 9 \%$ (range $39-65 \%$ ). Seven patients (30\%; Table IV) showed wall motion abnormalities. The duration of illness for patients having

Table III Echocardiographic measurements in asymptomatic patients with systemic sclerosis

$\begin{array}{ll}\text { LVIDd } & 4.27 \pm 0.61 \mathrm{~cm} \\ \text { LVIDs } & 2.76 \pm 0.46 \mathrm{~cm} \\ \text { IVS } & 0.93 \pm 0.02 \mathrm{~cm} \\ \text { LVPW } & 0.89 \pm 0.02 \mathrm{~cm} \\ \text { Aorta } & 2.79 \pm 0.46 \mathrm{~cm} \\ \text { LA } & 2.65 \pm 0.46 \mathrm{~cm} \\ \text { Mitral EF slope } & 9.08 \pm 2.60 \mathrm{~cm} \\ \text { RV } & 1.88 \pm 0.57 \mathrm{~cm} \\ \text { Ejection time } & 0.30 \pm 0.03 \mathrm{~s}\end{array}$

LVIDd = left ventricular internal dimension during diastole; LVIDs $=$ left ventricular internal dimension during systole; IVS = interventricular septum; LVPW = left ventricular posterior wall motion; $\mathrm{LA}=$ left atrial dimension; $\mathbf{R V}=$ right ventricular dimension; $\mathrm{EF}=$ ejection fraction. 
Table IV Clinical and nuclear angiographic data of 7 patients having abnormal nuclear angiographic findings

\begin{tabular}{cccccc}
$\begin{array}{l}\text { Patient } \\
\text { no. }\end{array}$ & Age & $\begin{array}{c}\text { Duration } \\
\text { of illness }\end{array}$ & Wall motion & $\begin{array}{c}\text { Ejection } \\
\text { fraction } \\
(\%)\end{array}$ & ECG \\
\hline 9 & 42 & 15 & diffuse hypokinesia & 42 & Normal \\
10 & 37 & 10 & diffuse hypokinesia & 55 & flat Tv4,V6 \& Q wave \\
20 & 50 & 14 & diffuse hypokinesia & 49 & Normal \\
21 & 70 & 16 & $\begin{array}{l}\text { diffuse hypokinesia } \\
\text { (mainly antero apical) }\end{array}$ & 48 & Normal \\
24 & 43 & 5 & diffuse hypokinesia & 39 & Normal \\
27 & 66 & 12 & diffuse hypokinesia & 39 & Normal \\
28 & 42 & 15 & diffuse hypokinesia & 39 & Normal \\
\hline
\end{tabular}

normal wall motion was $9.5 \pm 7 y$ while for those having abnormal wall motion it was $13 \pm 4 \mathrm{y}$. In the abnormal wall motion group ejection fraction was reduced to $44 \pm 6 \%$ compared to $60 \pm 6 \%$ of the group with normal wall motion $(P<0.01)$. Only 2 patients with normal wall motion had an ejection fraction of less than $55 \%(49 \%$ and $51 \%)$ which is the lower limit of normal in our laboratory. There was no significant difference in the mean age of the two groups $(50 \pm 13 \mathrm{y}$ for those having normal wall motion and $44 \pm 9.5 \mathrm{y}$ for those with abnormal wall motion).

All but one of the patients with wall motion abnormalities had a normal 12-lead electrocardiogram. In one case there were $Q$ waves and inverted or flat T waves in V4-V6. The 24 hour electrocardiogram revealed no difference in heart rate between the two groups. Diffuse wall motion abnormalities were observed in the patient who had ventricular tachycardia on the 24 hour electrocardiogram.

\section{Discussion}

In this non-invasive assessment of cardiac structure and function 15 of $28(54 \%)$ asymptomatic cardiac patients with progressive systemic sclerosis had some kind of otherwise occult cardiac involvement.

Fibrotic lesions of the myocardium suggestive of systemic sclerosis had been observed in $12-80 \%$ of patients from different series (D'Angelo et al., 1969; Bulkley et al., 1976; Botstein \& LeRoy, 1981; Sackner, 1966). Fibrosis may result in different clinical presentations including angina, myocardial infarction and arrhythmias even in the presence of normal coronary arteries (Bulkley et al., 1976; Oram \& Stokes, 1961).

Recently it has been shown that thallium-201 scintigrams and pyrophosphate scans can detect perfusion defects or cell necrosis in the myocardium in patients with systemic sclerosis (Alexander et al., 1981; Duska et al., 1982). Follansbee et al. (1984) studied 23 patients $(6,23 \%$, had clinical evidences of cardiac involvement) and found that 20 patients (77\%) had abnormal thallium redistribution scan. In the present study first pass nuclear ventriculography revealed diffuse wall motion abnormalities in $7 / 23$ patients $(30 \%)$. Previous studies, both in normal volunteers with a wide age range (Port $e t$ al., 1980) and in patients with abnormal exercise test but normal coronary arteries (Berger et al., 1981) have shown a normal left ventricular ejection fraction and wall motion. Given the good agreement between radionuclide and contrast angiography (Dymond et al., 1979) it is unlikely that the wall motion abnormalities detected in $30 \%$ of the patients in this study was due to an error in the method. This suggests a generalized distribution of the fibrotic lesions in the ventricular myocardium as described in histopathological studies (D'Angelo $e t$ al., 1969; Bulkley et al., 1976; Botstein \& LeRoy, 1981). The presence of fibrosis is not necessarily due to coronary artery disease because in most post-mortem studies these lesions were not associated with coronary artery involvement (Bulkley et al., 1976; Oram \& Stokes, 1961; Follansbee et al., 1984). The possibility of an ischaemic process in our patients who showed abnormal wall motion cannot be ruled out completely, but with one exception all these patients had a normal electrocardiogram (Table IV) and had no symptoms suggestive of ischaemia. Furthermore, in all the 7 patients there was diffuse rather than localized wall motion abnormalities. Nuclear angiography may therefore be a useful non-invasive test for detection of early myocardial involvement. In future studies the value of provocative manoeuvres such as exercise, cold pressor test should also be evaluated (Alexander $e t$ al., 1981; Montanes et al., 1982; Follansbee, 1984).

The 12-lead electrocardiogram revealed a partial and complete RBBB pattern in $18 \%$ of this group of patients while $1.4 \%$ was estimated in normal population (Ostrander et al., 1965). No other electrocardiographic abnormalities could be found. Escudero \& McDevitt (1958) demonstrated that $75 \%$ of patients with visceral involvement had abnormal surface electrocardiograms; mainly $\mathbf{P}$ wave notching, which was 
not observed in this series. The frequency of supraventricular and ventricular arrhythmias on the 24 hour ambulatory electrocardiogram in this series was relatively lower than others (Clements et al., 1981; Ridolfi et al., 1976) and did not differ from the spectrum of arrhythmias encountered among healthy middle-aged populations (Clarke et al., 1976; Verbaan et al., 1978) except for the relatively higher frequency of sinus arrhythmia. The difference between our results and those from other series may be due to patient selection since there was a high proportion of patients with clinical evidence of cardiac involvement in the other series (Clements et al., 1981; Ridolfi et al., 1976).

Many pathological studies (James, 1974; Roberts \& Cabeen, 1980; Clements et al., 1981; Lev et al., 1976) have shown a variable degree of sclerosis in the conduction system without any correlation with the electrocardiogram and arrhythmia pattern. It has been suggested that these lesions are probably a part of the diffuse myocardial involvement (Botstein \& LeRoy, 1981; Clements et al., 1981; Ridolfi et al., 1976); although focal changes in the specialized conduction tissue have been described (Roberts \& Cabeen, 1980). In this study there was no correlation between the electrocardiographic findings and either echocardiographic or nuclear angiographic data. In one series $70 \%$ of patients had abnormal findings during electrophysiological study and functional abnormalities of the sinoatrial and atrioventricular nodes were frequently encountered in these patients despite normal surface electrocardiograms (Clements et al., 1981; Ridolfi et al., 1976). The high incidence of RBBB in this series may suggest sclerotic involvement of the conducting tissue. This may have prognostic importance, because there have been reports of sudden death in systemic sclerosis patients with conducting tissue involvement (James, 1974; Roberts \& Cabeen, 1980).

Pericardial involvement is relatively common in systemic sclerosis. Seventy-two per cent of cases have shown some kind of acute or chronic fibrinous pericardial change at post-mortem (D'Angelo et al., 1969; Bjerregaard, 1983; McWhorter \& LeRoy, 1974). Such pericardial involvement has usually been clinically silent. Echocardiographic evidence of pericardial thickening was found in $50 \%$ of this group and 2 patients $(7 \%)$ had additional small pericardial effusions. This is significantly higher than the incidence of echocardiographically diagnosed pericardial thickening in a general hospital (173 of 9000 echocardiograms examined; Schnittger et al., 1978). Smith et al. (1979) found that $41 \%$ of unselected patients with progressive systemic sclerosis had pericardial effusions, but $32 \%$ of these patients had signs and symptoms of pericardial effusions. Echocardiography appears useful in the assessment of early pericardial involvement in these patients.

It is obvious from this study that nuclear angiography, 12-lead electrocardiography, echocardiography and 24 hour ambulatory electrocardiography are useful tools for discovering early cardiac involvement in patients with systemic sclerosis. The prognostic value of these investigations is still unclear and further long-term evaluation of these findings is necessary.

\section{Acknowledgement}

We are grateful to the cardiac and nuclear medicine staff at St. Bartholomew's Hospital for their help in this study. AJC is Sir Ronald Bodley Scott, Professor of Cardiovascular Medicine (supported by the British Heart Foundation) at St Bartholomew's Hospital.

\section{References}

ALEXANDER, E., HAUSER, R., WEISS, J.L., FIRESTEIN, G.S., LEITL, G., WAGNER, H.N., STEVENS, M.B. \& BECKER, L.C. (1981). Scleroderma heart disease: evidence for cold induced abnormalities of myocardial perfusion and function. Circulation, 64 (suppl. II), 24 (Abst.).

BERGER, H.J., SANDS, M.J., DAVIES, R.A., WACKERS, F.J.T., ALEXANDER, J., LACHMAN, A.S., WILLIAMS, B.W. \& ZARET, B.L. (1981). Exercise left ventricular performance in patients with chest pain, ischemic-appearing exercise electrocardiogram, and angiographically normal coronary arteries. Annals of Internal Medicine, 94, 186.

BJERREGAARD, P. (1983). Mean 24-hour heart rate, minimal heart rate pauses in healthy subjects $40-79$ years of age. European Heart Journal, 4, 44.

BOTSTEIN, G.R. \& LEROY, E.C. (1981). Primary heart disease in systemic sclerosis (scleroderma): advances in clinical and pathological features. Pathogenesis and new therapeutic approaches. American Heart Journal, 102, 913. BULKLEY, B.H., RIDOLFI, R.L., SALYER, W.R. \& HUT-

CHINS, G.M. (1976). Myocardial lesions of progressive systemic sclerosis, a cause of cardiac dysfunction. Circulation, 53, 483 .

BULKLEY, B.H., KLACSMANN, P.G. \& HUTCHINS, G.M. (1978). Angina pectoris, myocardial infarction and sudden cardiac death with normal coronary arteries: a clinicopathologic study of a patient with progressive systemic sclerosis. American Heart Journal, 95, 563.

CLARKE, J.M., SHELTON, J.R., HAMER, J., TAYLOR, S. \& VENNING, G.R. (1976). The rhythm of the normal heart. Lancet, ii, 508.

CLEMENTS, P.J., FRUST, D.E., CABEEN, W., TASHKIN, D., PAULUS, H.E. \& ROBERTS, N. (1981). The relationship of arrhythmias and conduction disturbances to other manifestations of cardiopulmonary disease in progressive systemic sclerosis (PSS). American Journal of Medicine, 71, 38.

D'ANGELO, W.A., FRIES, J.F., MASI, A.T. \& SHULMAN, L.E. (1969). Pathological observations in systemic sclerosis 
(scleroderma). A study of fifty-eight autopsy cases and fifty-eight matched controls. American Journal of Medicine, 46, 428.

DUSKA, F., BRADNA, P., NOVAK, J., KUBICEK, J., VIZDA, J., KAFKA, P., MAZUROVA, Y. \& BLAHA, V. (1982). Pyrophosphate heart scan in patients with progressive systemic sclerosis. British Heart Journal, 47, 90.

DYMOND, D.S., JARRITT, P.H., BRITTON, K.E. \& SPURRELL, R.A.J. (1979). Detection of post infarction left ventricular aneurysms by first pass radionuclide ventriculography using a multicrystal gamma camera. British Heart Journal, 41, 68.

DYMOND, D.S., CAMM, A.J., STONE, D.L., REES, G.M., REES, S. \& SPURRELL, R.A.J. (1980). Dual isotope stress testing in congenital atresia of the left coronary ostium: applications before and after surgical treatment. British Heart Journal, 43, 270.

ESCUDERO, J. \& MCDEVITT, E. (1958). The electrocardiogram in scleroderma. Analysis of 60 cases and review of the literature. American Heart Journal, 56, 846.

FOLLANSBEE, W.P., CURTISS, E.I., MEDSGER, T.A., STEEN, V.D., URETSKY, B.F., OWENS, G.R. \& RODNAN, G.P. (1984). Physiological abnormalities of cardiac function in progressive systemic sclerosis with diffuse scleroderma. New England Journal of Medicine, 310, 142.

JAMES, T.N. (1974). Desubitaneis mortibus VIII; Coronary arteries and conduction system in scleroderma heart disease. Circulation, 50, 844.

LEV, M., LANDOWNE, M., MATCHER, J.C. \& WAGNER, J.A. (1976). Systemic scleroderma with complete heart block. American Heart Journal, 72, 13.

LOWN, B. \& WOLF, M. (1971). Approaches to sudden death from coronary heart disease. Circulation, 44, 130.

MARINATO, P.G., THIENE, G., MENGHETTI, L., BUJA, G.F., NAVA, A., CECCHETTO, A. \& ROSSI, L. (1981). Clinicophathologic assessment of arrhythmias in a case of scleroderma heart disease with sudden death. European Journal of Cardiology, 12, 321.

MCWHORTER, J.E. \& LEROY, E.C. (1974). Pericardial disease in scleroderma (systemic sclerosis). American Journal of Medicine, 57, 566.

MONTANES, P., LOWLESS, C., BLACK, C. \& OAKLEY, C.M. (1982). The heart in scleroderma: non invasive assessment. Clinical Cardiology, 5, 383.

ORAM, S. \& STOKES, W. (1961). The heart in scleroderma. British Heart Journal, 23, 243.
OSTRANDER, L.D., BRANDTH, R.L. \& KJELSBERG, M.O. (1965). Electrocardiographic findings among the adult population of a total natural community, Tecumsch, Michigan. Circulation, 31, 888.

PORT, S., COBB, F.R., COLEMAN, E. \& JONES, R.H. (1980). Effect of age on the response of the left ventricular ejection fraction to exercise. New England Journal of Medicine, 303, 1133.

PRINEAS, R.J., CROW, R.S. \& BLACKBURN, H.B. (1982). In The Minnesota Code Manual of Electrocardiographic Findings. John Wright PSG: London.

RIDOLFI, R.L., BULKLEY, B.H. \& HUTCHINS, G.M. (1976). The cardiac conduction system in progressive systemic sclerosis, clinical and pathological features of 35 patients. American Journal of Medicine, 61, 361.

ROBERTS, N.K. \& CABEEN, W.R. (1980). Atrioventricular nodal function in progressive systemic sclerosis electrophysiological and morphological findings. British Heart Journal, 44, 529.

ROBERTS, N.K., CABEEN, W.R., MOSS, J., CLEMENTS, P.J. \& FURST, D.E. (1981). The prevalence of conduction defects and cardiac arrhythmias in progressive systemic sclerosis. Annals of Internal Medicine, 94, 38.

SACKNER, M.A., HEINZ, E.R. \& STEINBERG, A.J. (1966). The heart in scleroderma. American Journal of Cardiology, 17, 542.

SAHN, D.J., DEMARIA, A., KISSLO, J., KISSLO, J. \& WEYMAN, A. (1978). Recommendations regarding quantitation in $M$ mode echocardiography: results of a survey of echocardiographic measurements. Circulation, 58, 1072.

SCHNITTGER, I., BOWDEN, R.E., ABRAMS, J. \& POPP, R.L. (1978). Echocardiographic pericardial thickening and constrictive pericarditis. American Journal of Cardiology, 42, 388.

SMITH, J.W., CLEMENTS, P.J., LEVISMAN, J., FURST, D. \& ROSS, M. (1979). Echocardiographic features of progressive systemic sclerosis. American Journal of Medicine, 66, 28.

VERBAAN, C.J., POOL, J. \& VAN WANROOY, J. (1978). Incidence of cardiac arrhythmias in a presumed healthy population. In Proceedings of the Second International Symposium on Ambulatory Monitoring, Scott, F.D., Sleight, P., Raftery, E.B. \& Goulding, L. (eds) p. 1. Academic Press: London. 